\title{
Vaping-Related Mobile Apps Available in the Google Play Store After the Apple Ban: Content Review
}

\author{
Meredith C Meacham ${ }^{1}$, MPH, PhD; Erin A Vogel², PhD; Johannes Thrul ${ }^{3}, \mathrm{PhD}$ \\ ${ }_{1}^{1}$ Department of Psychiatry and Behavioral Sciences, University of California San Francisco, San Francisco, CA, United States \\ ${ }^{2}$ Stanford Prevention Research Center, Department of Medicine, Stanford University, Stanford, CA, United States \\ ${ }^{3}$ Department of Mental Health, Johns Hopkins School of Public Health, Baltimore, MD, United States
}

\section{Corresponding Author:}

Meredith C Meacham, MPH, PhD

Department of Psychiatry and Behavioral Sciences

University of California San Francisco

401 Parnassus Ave

San Francisco, CA, 94143

United States

Phone: 14152064253

Email: Meredith.Meacham@ucsf.edu

\section{Abstract}

Background: In response to health concerns about vaping devices (eg, youth nicotine use, lung injury), Apple removed 181 previously approved vaping-related apps from the App Store in November 2019. This policy change may lessen youth exposure to content that glamorizes vaping; however, it may also block important sources of information and vaping device control for adults seeking to use vaping devices safely.

Objective: Understanding the types of nicotine and cannabis vaping-related apps still available in the competing Google Play Store can shed light on how digital apps may reflect information available to consumers.

Methods: In December 2019, we searched the Google Play Store for vaping-related apps using the keywords "vape" and "vaping" and reviewed the first 100 apps presented in the results. We reviewed app titles, descriptions, screenshots, and metadata to categorize the intended substance (nicotine or cannabis/tetrahydrocannabinol) and the app's purpose. The most installed apps in each purpose category were downloaded and evaluated for quality and usability with the Mobile App Rating Scale.

Results: Of the first 100 apps, 79 were related to vaping. Of these 79 apps, 43 (54\%) were specific to nicotine, 3 (4\%) were specific to cannabis, $1(1 \%)$ was intended for either, and for the remaining $31(39 \%)$, the intended substance was unclear. The most common purposes of the apps were making do-it-yourself e-liquids $(28 / 79,35 \%)$ or coils $(25 / 79,32 \%)$, games/entertainment $(19 / 79,24 \%)$, social networking $(16 / 79,20 \%)$, and shopping for vaping products $(15 / 79,19 \%)$. Of the 79 apps, at least 4 apps $(5 \%)$ paired with vaping devices to control temperature or dose settings, 8 apps (10\%) claimed to help people quit smoking using vaping, and 2 apps (3\%) had the goal of helping people quit vaping.

Conclusions: The majority of vaping-related apps in the Google Play Store had features either to help users continue vaping, such as information for modifying devices, or to maintain interest in vaping. Few apps were for controlling device settings or assisting with quitting smoking or vaping. Assuming that these Google Play Store apps were similar in content to the Apple App Store apps that were removed, it appears that Apple's ban would have a minimal effect on people who vape with the intention of quitting smoking or who are seeking information about safer vaping via mobile apps.

(J Med Internet Res 2020;22(11):e20009) doi: $\underline{10.2196 / 20009}$

\section{KEYWORDS}

vaping; mobile apps; nicotine; cannabis 


\section{Introduction}

\section{Background}

The emergence of vaping, or e-cigarette technology, whereby a liquid solution is heated in a portable device until aerosolized and then inhaled, has been greeted with both promise and alarm [1-4]. In response to concerns about lung injury associated with vaping [5] and the increasing prevalence of youth vaping [6,7], Apple removed previously-approved vaping-related apps from its App Store (for iOS) in November 2019 [8], but the competing Google Play Store (for Android) did not remove vaping-related apps. Vaping-related apps may negatively influence youth by glamorizing vaping; however, some apps may benefit adults who use tobacco by providing cessation assistance or harm reduction information. The net balance of benefits and drawbacks from vaping-related apps likely depends on app content.

\section{Vaping Nicotine}

Vaping nicotine may be less harmful than smoking combustible cigarettes [9] and may be a potential tool in helping people quit smoking $[4,10,11]$. Yet, alongside this potential is limited scientific evidence about the efficacy of nicotine vaping in promoting and maintaining tobacco-smoking cessation, as well as mounting concerns about a youth vaping epidemic $[12,13]$. Evidence to date appears to be mixed and context-dependent regarding whether e-cigarettes help adults quit [10] with concerns that the amount of nicotine in popular vaping products is too high and that people who quit smoking by vaping may return to smoking [1].

E-cigarettes are currently the most popular tobacco product among US youth, with an estimated 1 in 5 US high-school seniors reporting having vaped nicotine in the previous month, and 1 in 4 reporting having vaped nicotine- or flavor-containing e-liquids in 2018 [6]. A higher past-month prevalence of vaping was reported in the 2019 National Youth Tobacco Survey, with more than 1 in 4 US high-school students using e-cigarettes [7]. Although adolescents are smoking fewer cigarettes per day [14], and smoking has become less prevalent [15] in recent years, there are also reports of greater nicotine dependence among adolescents and young adults who vape prefilled pods (cartridges) [16], and a body of research indicating harm to the developing brain from nicotine [17]. In response, national and local governments have taken steps to propose or enact restrictions (or bans) on e-cigarette sales $[18,19]$ and flavored vaping products [20].

\section{Vaping Cannabis}

Similarly, vaping cannabis extracts or flower is believed to be less harmful than inhaling combusted cannabis [21-23]. Vaping is an increasingly popular method of cannabis consumption in the United States [24-26] although cannabis remains illegal in many US states and most countries. Both formal and informal cannabis product markets now offer a wide array of ways to consume tetrahydrocannabinol (THC), including vaping products [2,27]. The legalization of cannabidiol from hemp products in the United States in 2018 has led to an increase in interest and availability of cannabidiol-containing products [28] some of which can be vaped and do not need to be legally purchased from a licensed dispensary. Many vaping products with both THC and cannabidiol are sold online with limited regulation, and published product testing studies have found that tested cannabinoid content was often higher or lower than labeled content [29,30]. While Canada legalized cannabis nationally in October 2018, extracts and edibles were not legal until October 2019, due to additional difficulties in regulation.

Against this background, in the spring and summer of 2019, cases of acute lung injury related to vaping began to be reported in the United States. This new illness, named electronic or vaping product use associated lung injury (EVALI), ultimately caused at least 52 deaths and over 2600 hospitalizations by December 2019 [5]. Most of these patients were young adults who were previously healthy and reported a gradual onset of respiratory, constitutional, and gastrointestinal symptoms. Most — though not all—patients reported having used e-cigarette or vaping products containing THC. The most likely culprit was identified as vitamin $\mathrm{E}$ acetate, used as a bulking agent in primarily THC-containing vaping products, often procured in a state where cannabis was still illegal or from an unlicensed seller [31-34]. People who vape cannabis or nicotine may turn to mobile apps for guidance on safe use.

\section{Google Play Store Versus Apple iOS App Store}

Mobile phones and mobile apps are increasingly used for accessing health and safety information about many topics $[35,36]$, including substances. Apps are most used by younger populations with higher income and education [37]. The Google Play Store for Android and the Apple App Store for iOS are the 2 major mobile app platforms and marketplaces for digital apps, with 2.6 million available apps on Google Play and 1.8 million apps available on the Apple App Store in early 2020 [38]. Many popular apps have versions for both platforms. Both app stores have content, technical, and stylistic guidelines that developers must follow in order to have their app approved; violations can be grounds for removal of a previously approved app. It is generally believed that getting approval from the Apple App Store is more difficult than getting approval from the Google Play Store [39], with Apple App Store apps often viewed as higher quality and less likely to be free to use [40].

Both app stores specifically address tobacco and cannabis content in their developer guidelines (Table 1). Google Play Store's substance-related content guidelines prohibit apps "facilitating the sale" of tobacco, marijuana, alcohol, or illegal drugs, or those "depicting or encouraging" use by minors [41]. The Apple App Store guidelines prohibit apps that "encourage consumption of tobacco and vape products, illegal drugs, or excessive amounts of alcohol," particularly those encouraging minors [42]. Facilitating sale of these substances is also not allowed [42]. 
Table 1. App Store Review Guidelines related to tobacco, vaping, and marijuana.

\begin{tabular}{ll}
\hline App store and section & Text quotation \\
\hline Apple App Store for iOS & \\
Safety & $\begin{array}{l}\text { 1.4.3 Apps that encourage consumption of tobacco and vape products, il- } \\
\text { legal drugs, or excessive amounts of alcohol are not permitted on the App }\end{array}$ \\
& $\begin{array}{l}\text { Store. Apps that encourage minors to consume any of these substances } \\
\text { will be rejected. Facilitating the sale of marijuana, tobacco, or controlled } \\
\text { substances (except for licensed pharmacies) isn't allowed. [42] }\end{array}$
\end{tabular}

\section{Google Play Store for Android}

Illegal Activities

Inappropriate Content-Marijuana

Inappropriate Content—Tobacco \& Alcohol
We don't allow apps that facilitate or promote illegal activities.

Examples of common violations

Facilitating the sale or purchase of illegal drugs or prescription drugs without a prescription.

Depicting or encouraging the use or sale of drugs, alcohol, or tobacco by minors.

Instructions for growing or manufacturing illegal drugs. [41]

We don't allow apps that facilitate the sale of marijuana or marijuana products, regardless of legality.

Allowing users to order marijuana through an in-app shopping cart feature.

Assisting users in arranging delivery or pick up of marijuana.

Facilitating the sale of products containing THC (Tetrahydrocannabinol), including products such as CBD oils containing THC. [41]

We don't allow apps that facilitate the sale of tobacco (including ecigarettes and vape pens) or encourage the illegal or inappropriate use of alcohol or tobacco.

Depicting or encouraging the use or sale of alcohol or tobacco to minors. Implying that consuming tobacco can improve social, sexual, professional, intellectual, or athletic standing.

Portraying excessive drinking favorably, including the favorable portrayal of excessive, binge or competition drinking. [41]

\section{Apple iOS App Store's Vaping App Ban}

In response to health concerns about vaping devices (eg, youth nicotine use, lung injury) and calls for bans on nicotine flavors and vaping devices, Apple prohibited new vaping-related mobile apps from its iOS App Store in June 2019 and removed 181 previously approved vaping-related apps on November 15, 2019 $[8,43]$. Articles published on technology, vaping, and cannabis industry-affiliated websites in the following weeks decried this move by Apple, stating that the ban impacted device users' ability to safely use their products [44], removed a resource that assists people with quitting smoking [45], and would have detrimental effects on innovation [45], and that the app store approval process was inconsistent [46].

At a time of escalating concern about vaping, Apple's policy change may benefit public health by lessening youth exposure to content that glamorizes vaping. Exposure to vaping-related content online has been associated with greater intentions to vape [47] and greater likelihood of vaping [48] among youth. However, Apple's restrictions may also block important sources of information and vaping device control for adults seeking to use vaping devices safely.

The content and evidence base of vaping-related apps is currently unknown, though previous reviews and content analyses have examined apps related to smoking cessation, cannabis, alcohol [49], and other substance use [50]. Smoking cessation apps are abundant, though few have been demonstrated to be evidence-based [51-55], and many have limitations with usability [56]. A review [57] of cannabis apps conducted in 2014 found that the most common content areas largely consisted of cannabis strain classification guides, factoids about cannabis, and games, but few apps addressed negative health effects of cannabis use. To gain insight into the potential positive and negative effects of removing vaping-related apps from app stores, characterization of the remaining vaping-related apps in the Google Play Store, the main competing source for mobile apps, is an imperative first step.

\section{Study Objective}

We analyzed the top vaping-related mobile apps on the Google Play Store with respect to app characteristics, intended purpose, and provision of features and information for limiting the potential harms of smoking and vaping. To our knowledge, the Google Play Store did not enact any restrictions on vaping-related apps in response to EVALI. Within the context of government and industry regulatory policy changes surrounding vaping devices, understanding the types of apps available for mobile phones and tablets can shed light on how this form of digital media may reflect and influence information about nicotine and cannabis vaping available to consumers. Depending on their purposes and features, vaping-related apps 
could encourage or discourage vaping. Some apps may provide resources for adults seeking to switch to vaping from smoking or to use vaping devices safely, while others may negatively impact youth by glamorizing vaping. As such, the removal of vaping-related apps may have mixed effects on population health, depending on which types of content predominate.

\section{Methods}

\section{Selection of Apps}

A search for apps using the keywords vape and vaping was performed on the Google Play Store on December 17, 2019 from an IP address in the United States. The names and order of the first 100 apps displayed in response to the search query were recorded. Similar to previous studies reviewing apps, only the first 100 apps of 250 search results were examined, because it is unlikely that individuals would browse further for a desired app without refining their search terms [56-58]. We chose not to include $e$-cigarettes or $e$-cigs as search terms because of their infrequent use outside of academic and regulatory discourses.

Resulting vaping apps available in the Google Play Store served as a proxy for apps that may have been available in the Apple App Store prior to November 2019, as a list of removed apps was not publicly available. Thus, coding vaping-related apps in the Google Play Store provided insight into the types of the apps both currently available to Google Play Store customers and previously available to Apple App Store customers. A search for vaping and vape in the Apple App Store in December 2019, performed on both a Mac and an iPhone, yielded zero results on the Mac Store and yielded only apps related to quitting vaping or to vapor-like image effects in the iPhone app store.

\section{Rating of Apps}

Three investigators (MM, EV, JT) each extracted app characteristics directly from the Google Play Store for one-third of the apps (33-34 apps per investigator). Extracted app characteristics included the developer name, content and age ratings, cost, average star ratings, number of reviewers, number of installations, last date updated, and URL. An app purpose coding guide assessed whether the app was relevant to vaping (yes or no), the intended substance (nicotine/tobacco, cannabis/THC, or unclear), and the purpose of the app.

The app purpose coding guide was initiated by MM and developed iteratively among the investigators. Any information on the app store webpage, including description and screenshots, was used for coding the app purpose and content. Apps could have multiple purposes. After initial coding, the investigators discussed tabulated results and aspects of the coding guide that were unclear, then refined the coding guide based on common patterns and any confusing aspects of the coding guide.

The second coding guide was then applied to $20 \%$ of the apps, which were triple coded. Each investigator coded 21 apps (7 recoded from their first pass, with 7 each from the 2 other coders). Unanimous agreement across all 3 investigators was then assessed for the app's relevance to vaping (yes or no), intended substance (nicotine/cannabis/unclear), and each of 10 potential purpose categories (coils, e-liquids, mods, shopping, games, social, device, quitting smoking, quitting vaping, other).
If an app was determined to be about something other than vaping, its purpose was not coded. Agreement before consensus was 19/21 (90\%) for relevance to vaping, 12/17 (71\%) intended substance, and 14-17/17 (82\%-100\%) for the purpose categories. Individual apps for which at least one investigator had a discordant code were discussed until consensus was reached.

A third and final coding guide was applied to the full list of apps. Of note, the coding guide was clarified so that apps referencing heat-not-burn were coded as vaping-related. While tobacco heat-not-burn devices are considered distinct from vaping devices, heat-not-burn of cannabis flower is often considered vaping, and neither involves combustion. Additionally, the group could not determine the purpose of 6 apps from the Google Play Store descriptions. These apps were downloaded and evaluated using additional information from the downloaded app itself.

The final 8 purpose categories were do-it-yourself (DIY) coils, DIY e-liquids, shopping, entertainment, social, device, quitting smoking, and quitting vaping. Summary percentages and means for app metadata and purposes were calculated.

\section{Selection and Evaluation of Downloaded Apps}

Next, apps within each of the 8 purpose categories were ranked by total number of installs, and the top 2 to 5 apps per category were downloaded for review. Instead of ranking the most popular apps, we ranked apps by popularity within categories, so that apps with less overall popularity but potentially important purposes would be included. The number of apps selected per category varied due to ties in the reported number of installs. Because apps could have multiple categories, this procedure resulted in a list of 18 apps with 10 to 1 million downloads each. Three of these apps disappeared from the store before they could be downloaded for review; one could be replaced with a premium version of the same app. A total of 16 apps were downloaded onto 2 Samsung Galaxy Tab A tablets and a Google Pixel 2 smartphone.

A random selection $(6 / 16,38 \%)$ was reviewed by all 3 investigators. Discrepancies were discussed, and the coding guide was updated. The final coding guide included evaluations of whether the content of the downloaded app matched the purpose category (yes or no) and whether it had the following types of information (yes or no): information about harms of vaping (eg, lung injury, nicotine dependence), information about safer vaping or DIY device use (eg, how to prevent explosions), and information about harms of smoking (eg, nicotine dependence, cardiovascular harms, cancer risk). For apps coded as being intended for quitting smoking or quitting vaping, the presence of a tracking feature in the downloaded app (eg, tracking days without smoking or vaping, tracking money saved) was noted (yes or no). For apps coded as pairing with devices, the presence of features for tracking temperature, dosage, or device locking was noted (yes or no). Differences between investigators were discussed until consensus was reached.

Finally, the Mobile App Rating Scale (MARS) was applied to all 16 downloaded apps. The MARS is 23 -item multidimensional measure for rating the quality of mobile health apps, with 5 subscales in the areas of engagement ( 5 items), functionality (4 
items), aesthetics (3 items), information (7 items, including affiliation of developer), and subjective rating (4 items) [59]. Subjective rating was not applied as these items involve hypothetical personal use. Each item was rated on a scale of 1 to 5 , and ratings that differed by more than 2 points between investigators (eg, ratings of 1 vs 4 or 2 vs 5) were discussed. Investigators could adjust their ratings after discussion before averaging scores and did so 7 times across the 5 discussed apps. Some information items were rated as not applicable (N/A) and were excluded from average score calculations. For example, the item about meeting goals would be rated as N/A if the app purpose was not related to quitting smoking or vaping, and the visual information item would be rated as N/A if the app only contained text. Other smaller discrepancies were averaged without further discussion. Average ratings were calculated for each of the 4 subscales (engagement, functionality, aesthetics, information) and then averaged across the 3 investigator ratings. A final score was averaged for all downloaded apps and within each category.

\section{Results}

\section{Overview of Vaping Apps}

Of the top 100 apps captured by our search in December 2019, $79(79 \%)$ were determined to be about vaping and were coded for purpose and other features. It was determined that 15 of the 21 apps not about vaping referred to cigarette smoking or only smoking cessation. An additional 6 apps could not be found again during content coding in January 2020 and February 2020 and were removed from the analysis. There were 4 sets of apps with both free and pro versions. The pro version typically cost money to download and did not have advertisements or had additional features. All app descriptions were in English, though some apps appeared to have content in other languages.

Of the 79 apps, most apps were free $(60,76 \%)$ or free with in-app purchases $(13,16 \%)$; 6 apps cost between US \$0.99 and US $\$ 6.99$ to download. Over half the apps had in-app advertisements $(45,57 \%)$. Only one-third of apps $(36,33 \%)$ were rated as Mature $17+$, while the rest were rated as Teen $(13,16 \%)$ or Everyone $(40,51 \%)$ (Table 2).

There were 15 different Google Play Store-provided categories displayed with the app description, with the most common being tools and lifestyle, followed by health and fitness, simulation, and social. As one indicator of popularity, app downloads or installations ranged from at least 10 installs to over 1 million installs, with the first 10 apps presented in the search having at least 10,000 installs. As another set of popularity indicators, the average for the 68 apps with ratings was 4.0 stars, with a range of 2.5-5.0 stars by an average of 770 raters.

Investigator-coded app purposes are described in Table 2. The most common investigator-coded app purposes were creating DIY vaping e-liquids $(28 / 79,35 \%)$ and coils $(25 / 79,32 \%) ; 16$ apps $(16 / 79,20 \%)$ were coded as for both creating coils and e-liquids. The next most common purposes were entertainment or games $(19 / 79,24 \%)$, social networking with other app users $(16 / 79,20 \%)$, and shopping $(15 / 79,19 \%)$. Social and shopping also tended to be co-occurring purposes (10/79, \%). Finally, apps to help people quit smoking $(8 / 79,10 \%)$, directly control vaping devices $(4 / 79,5 \%)$, and quit vaping were less common $(2 / 79,3 \%)$. Out of 8 apps with quitting smoking features (typically a "cigarettes avoided" widget), 7 were also coded as DIY e-liquid or coil purposes. The majority referred to vaping with nicotine $(43 / 79,54 \%)$. Few apps were intended for cannabis $(3 / 79,4 \%)$, and 1 app referred to both nicotine and cannabidiol from cannabis $(1 / 79,1 \%)$. The intended substance was unclear in the remaining apps $(31 / 79,39 \%)$ (Table 3$)$.

Because apps could fall into multiple categories, we did not statistically test differences in star ratings. However, we noted that the highest rated apps by users were in the DIY e-liquids and quitting smoking and vaping categories, while the lowest were in the device category. The most popular apps by number of installations were in the DIY e-liquids, DIY coils, and entertainment categories. 
Table 2. Overview of vaping apps on Google Play Store in December 2019 (N=79).

\begin{tabular}{|c|c|}
\hline Characteristic & Value, $\mathrm{n}(\%)$ \\
\hline \multicolumn{2}{|l|}{ Cost } \\
\hline Price $\$ 0.99-\$ 6.99$ & $6(8)$ \\
\hline In-app purchases & $13(16)$ \\
\hline Free & $60(76)$ \\
\hline \multicolumn{2}{|l|}{ Advertisements } \\
\hline Yes & $45(57)$ \\
\hline No & $34(43)$ \\
\hline \multicolumn{2}{|l|}{ Age rating } \\
\hline Everyone & $40(51)$ \\
\hline Teen & $13(16)$ \\
\hline Mature $17+$ & $26(33)$ \\
\hline \multicolumn{2}{|l|}{ Categories } \\
\hline Tools & $25(32)$ \\
\hline Lifestyle & $22(28)$ \\
\hline Health and fitness & $5(6)$ \\
\hline Simulation & $4(5)$ \\
\hline Social & $4(5)$ \\
\hline Art and design & $4(5)$ \\
\hline Other $^{\mathrm{a}}$ & $15(19)$ \\
\hline \multicolumn{2}{|l|}{ Other content ratings } \\
\hline Use of tobacco & $7(9)$ \\
\hline Use of drugs & $3(4)$ \\
\hline Drug reference & $1(1)$ \\
\hline Tobacco reference & $1(1)$ \\
\hline Language & $1(1)$ \\
\hline Violence, blood & $1(1)$ \\
\hline \multicolumn{2}{|l|}{ Total installs } \\
\hline 10 to 500 & $13(16)$ \\
\hline 1000 to 5000 & $36(46)$ \\
\hline 10,000 to 50,000 & $20(25)$ \\
\hline 100,000 & $8(10)$ \\
\hline $1,000,000$ & $2(3)$ \\
\hline \multicolumn{2}{|l|}{ Ratings } \\
\hline Stars out of $5(n=68)$, mean $(S D)$ & $4(0.7)$ \\
\hline Raters (n=68), mean (SD) & $770(2607)$ \\
\hline \multicolumn{2}{|l|}{ Last updated } \\
\hline 2013-2016 & $13(16)$ \\
\hline 2017 & $11(14)$ \\
\hline 2018 & $24(30)$ \\
\hline 2019 (through November 14) & $13(16)$ \\
\hline November 15, 2019-February 29, 2020 & $18(23)$ \\
\hline
\end{tabular}


${ }^{\mathrm{a} O t h e r ~ i n c l u d e s ~ a d v e n t u r e, ~ e d u c a t i o n, ~ e n t e r t a i n m e n t, ~ l i b r a r i e s ~ a n d ~ d e m o, ~ m a p s ~ a n d ~ n a v i g a t i o n, ~ m e d i c a l, ~ m u s i c ~ a n d ~ a u d i o, ~ p e r s o n a l i z a t i o n, ~ p r o d u c t i v i t y, ~}$ and travel and local categories.

Table 3. Purpose and intended substance ratings for vaping apps on Google Play Store (N=79).

\begin{tabular}{|c|c|c|c|c|c|}
\hline Category & Description & Apps, n (\%) & $\begin{array}{l}\text { With star } \\
\text { ratings, } \mathrm{n}\end{array}$ & $\begin{array}{l}\text { Star rating, } \\
\text { mean }(\mathrm{SD})\end{array}$ & Installations, $\mathrm{n}$ \\
\hline \multicolumn{6}{|l|}{ Purpose $^{\mathbf{a}}$} \\
\hline DIY $Y^{b}$ e-liquids & $\begin{array}{l}\text { Has features for creating e-liquids (eg, calculators with } \\
\text { nicotine and propylene glycol or vegetable glycerin inputs, } \\
\text { e-liquid recipes) }\end{array}$ & $28(35)$ & 26 & $4.18(0.60)$ & $500+$ to $1,000,000+$ \\
\hline DIY coils & $\begin{array}{l}\text { Has features for designing coils for DIY mods (eg, Ohm's } \\
\text { law calculators) }\end{array}$ & $25(32)$ & 25 & $4.01(0.68)$ & $500+$ to $1,000,000+$ \\
\hline Entertainment & Simulations, wallpapers, games & $19(24)$ & 14 & $3.74(0.65)$ & $100+$ to $1,000,000+$ \\
\hline Social & $\begin{array}{l}\text { Has features for connecting with other app users or people } \\
\text { who vape, including the ability to review products }\end{array}$ & $16(20)$ & 15 & $4.03(0.79)$ & $50+$ to $100,000+$ \\
\hline Shopping & $\begin{array}{l}\text { For finding products or stores that sell vaping devices or } \\
\text { products or e-liquids }\end{array}$ & $15(19)$ & 13 & $3.92(0.93)$ & $50+$ to $100,000+$ \\
\hline Quitting smoking & $\begin{array}{l}\text { For helping people quit smoking (using vaping or not); } \\
\text { may include a tracking feature oriented around not using } \\
\text { cigarettes }\end{array}$ & $8(10)$ & 8 & $4.06(0.52)$ & $500+$ to $10,000+$ \\
\hline Device & Pairs with and has features for modifying a device & $4(5)$ & 2 & $2.65(0.07)$ & $100+$ to $10,000+$ \\
\hline Quitting vaping & For helping people quit vaping & $2(3)$ & 1 & $4.10\left(\mathrm{~N} / \mathrm{A}^{\mathrm{c}}\right)$ & $10+$ to $1000+$ \\
\hline \multicolumn{6}{|l|}{ Substance } \\
\hline Cannabis & N/A & $3(4)$ & 2 & $3.55(1.34)$ & $100+$ to $10,000+$ \\
\hline Nicotine & N/A & $43(54)$ & 38 & $3.97(0.62)$ & $10+$ to $1,000,000+$ \\
\hline Unclear & N/A & $31(39)$ & 26 & $4.07(0.78)$ & $50+$ to $100,000+$ \\
\hline Both & N/A & $1(1)$ & 1 & 4.70 (N/A) & $10,000+$ \\
\hline
\end{tabular}

${ }^{\mathrm{a} A p p s}$ could have multiple purposes.

${ }^{b}$ DIY: do-it-yourself.

${ }^{\mathrm{c}} \mathrm{N} / \mathrm{A}$ : not applicable.

\section{Downloaded Apps}

The majority of downloaded apps $(14 / 16,88 \%)$ matched the descriptions in the app store (Table 4). The exceptions were that 1 app coded as having quitting smoking features did not have any such features, and 1 app that was coded as not having shopping features did, in fact, have links to shopping through the app. Few apps had information about harms of vaping (4/16, $25 \%)$, safer vaping $(3 / 16,19 \%)$, or harms of smoking $(2 / 16$, $13 \%)$. When they did have such information, it was often difficult to find. Of note, 2 of the entertainment apps had a feature where an avatar would cough when vaping too much, which may normalize moderation in vaping; 5 apps had tracking features, which mainly recorded days passed since a user-provided quit-smoking date; and 2 of the apps with tracking features also displayed money saved and health benefits. Both device apps appeared to have temperature controls, but did not have dosage or locking settings visible, though these may have become apparent once paired with a device.

Overall, the 16 downloaded apps had a mean MARS score of 3.63, with a highest mean subscore for functionality (MARS score: mean 4.13) and lowest mean subscore for engagement (MARS score: mean 3.36). Within the subtypes of purposes, the highest mean MARS scores were for social, shopping, and device apps, and the lowest mean scores were for the quitting smoking and DIY coils apps. 
Table 4. Ratings of downloaded vaping apps $(\mathrm{N}=16)$.

\begin{tabular}{|c|c|}
\hline Characteristic and subcharacteristic & Value \\
\hline \multicolumn{2}{|l|}{ Purpose, n (\%) } \\
\hline Matches coded purpose & $14(88)$ \\
\hline \multicolumn{2}{|l|}{ Information, $\mathrm{n}(\%)$} \\
\hline Harms of vaping & $4(25)$ \\
\hline Safer vaping & $3(19)$ \\
\hline Harms of smoking & $2(13)$ \\
\hline \multicolumn{2}{|l|}{ Behavior change, $n(\%)$} \\
\hline Tracking feature & $5(31)$ \\
\hline \multicolumn{2}{|l|}{ Device (n=2), n (\%) } \\
\hline Temperature & $2(100)$ \\
\hline Dosage & $0(0)$ \\
\hline Locking & $0(0)$ \\
\hline \multicolumn{2}{|c|}{ MARS $^{\mathrm{a}}$ (out of 5, all downloaded apps), mean (range) } \\
\hline Engagement & $3.36(2.80-4.20)$ \\
\hline Functionality & $4.13(3.08-4.58)$ \\
\hline Aesthetics & $3.40(2.22-4.50)$ \\
\hline Information & $3.61(2.50-4.83)$ \\
\hline Summary & $3.63(2.77-4.47)$ \\
\hline \multicolumn{2}{|c|}{ MARS (out of 5 , by purpose category) ${ }^{\mathbf{b}}$, mean (range) } \\
\hline DIY $^{\mathrm{c}}$ e-liquids $(\mathrm{n}=5)$ & $3.54(3.16-4.04)$ \\
\hline DIY coils $(n=3)$ & $3.44(3.16-3.89)$ \\
\hline Entertainment $(\mathrm{n}=3)$ & $3.66(3.00-4.47)$ \\
\hline Social $(n=3)$ & $4.22(4.04-4.47)$ \\
\hline Shopping ( $\mathrm{n}=2$ ) & $4.09(4.04-4.15)$ \\
\hline Quitting smoking $(\mathrm{n}=2)$ & $3.08(2.89-3.49)$ \\
\hline Device $(\mathrm{n}=2)$ & $4.04(3.93-4.15)$ \\
\hline Quitting vaping ( $\mathrm{n}=2$ ) & $3.93(3.80-4.06)$ \\
\hline
\end{tabular}

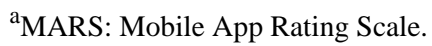

${ }^{\mathrm{b}}$ Top 2 to 5 apps per category by number of installations; categories with 3 to 5 apps had ties in the number of installations.

${ }^{\mathrm{c} D I Y}$ : do-it-yourself.

\section{Discussion}

This study examined the content of the first 100 mobile apps on the Google Play Store using vaping and vape as search terms 1 month after Apple's ban on vaping-related apps, which was enacted in response to concerns about youth nicotine vaping and EVALI (a lung injury syndrome linked to an additive to cannabis vaping products). Of 79 apps determined to be related to vaping, over half were related to nicotine, while only a few were for cannabis, and the rest were unclear in intended substance. The most popular app content, with respect to both number of installations (several with over 1 million) and percentage of these 79 vaping apps, was creating DIY liquids $(28 / 79,35 \%)$ and DIY coils $(25 / 79,32 \%)$, with $20 \%$ (16/79) in both categories (37 total). This may reflect a strong interest in
DIY hobbies in vaping culture. DIY may allow users to control the customization process, play with novelty, save money, and achieve higher nicotine concentrations [60,61]. Overall, the main purposes of the majority of these vaping-related apps on the Google Play Store were to help people continue to vape nicotine.

Apps that had features to support quitting smoking or vaping were relatively rare $(8 / 79,10 \% ; 2 / 79,3 \%$; respectively). Most apps that supported smoking cessation encouraged users to quit smoking by switching to vaping. These apps also contained other features to promote or facilitate vaping, such as e-liquid recipes. The 2 apps for quitting vaping that were downloaded had above average MARS scores but relatively few installations, while the 3 apps for quitting smoking that were downloaded had below average MARS scores and low subscores on 
aesthetics and information. This points to the need for apps to promote vaping cessation using evidence-based behavior-change information and strategies, along with engaging usable interfaces.

There were also few apps that paired with devices (4/79, 5\%), and these device apps were mainly for cannabis. Devices that pair with apps using Bluetooth technology are more expensive, which may explain their lower popularity in terms of installs. Features available in the downloaded device apps indicated that the user could control temperature [62], which may limit throat and lung damage, but not dosage, and there were no locking controls for users with children or those wishing to moderate their use.

Given current concerns about youth vaping, the findings that over half the apps had no age controls and that a large proportion of apps without age controls was in the DIY categories (24/37, $65 \%$ ) are especially concerning. A smaller proportion of entertainment apps had no age controls $(5 / 19,26 \%)$, though many of the apps with age controls were set at Teen. Age controls may allow parents who utilize family controls to restrict their children's access to these apps.

Of the popular apps that were downloaded and reviewed in-depth, few apps presented information about the harms of vaping or smoking or included information about safer vaping. Information about harms of smoking consisted of articles comparing the harms of smoking (eg, combustion and cancer-causing ingredients) to vaping. One app had a widget for tracking "days without smoking" that included "gained days of life" and "avoided radiographs" calculations.

Information presented about harms of vaping included acknowledgments of the importance of moderating nicotine intake, the addictiveness of nicotine, or harms of vaping in front of children. The 2 downloaded apps that were intended to help people quit vaping both included links to news stories about young adults with EVALI and articles about concerns with youth vaping and the intentions of vaping companies. Safer vaping information included recommendations about coil and battery materials, causes of e-cigarette explosions, and cautions against mixing e-liquids incorrectly. It should be noted that in 2 entertainment apps with simulated vaping games, the vaping avatar would cough audibly when they "inhaled" a large amount of vapor, which could be seen as encouraging moderation in use. Several of these apps included a tracking feature that displayed the number of days since quitting smoking and the number of cigarettes avoided. Self-monitoring is an important component of a smoking cessation plan but is likely insufficient by itself [63]. In addition to a need for apps on the Google Play store that assist people with quitting vaping, study results indicate a need for informational apps to better describe the pros and cons of vaping.

Assuming that these Google Play Store apps were similar in content to the Apple App Store apps that were removed, it appears that Apple's ban would have had a minimal effect on people who vape with the intention of quitting smoking or who are seeking information about safer vaping. Nevertheless, the decision to remove the vaping-related apps appears to have been taken by Apple in response to rising EVALI cases, which were primarily attributed to cannabis oil additives, rather than nicotine liquids $[33,34]$. There appeared to be little publicly available information detailing how apps were determined to be removed, echoing other calls for increased transparency and additional research regarding allowed app platform content and other issues like privacy $[39,64]$. Future research should explore other cases touching on the who and how of regulation of apps related to controversial health-behavior for which there is not yet a consensus among health experts. Future research should also examine more explicitly the relationship between vaping app use and vaping behaviors.

There were several limitations to this study. First, not all apps that came up in the initial search were reviewed, though most app users would likely not browse more than 100 apps without refining their search. Additionally, the app store gets updated continuously, and a search on a different date may present different results. Indeed, several apps were no longer available a few weeks after the initial search. While the number of installations was recorded for each as a signal of popularity, people may download an app and not use it at all or only use it a limited number of times. Only 1 of the reviewed apps was also available on the iPhone App Store, but it is unclear which of the apps we reviewed were removed from or denied approval in the Apple App Store. Although we only coded Google Play Store apps, a search for vaping in the mobile Apple App Store in December 2019 confirmed that the remaining apps were related to quitting smoking or quitting vaping or were unrelated to vaping behavior.

Based on this review of vaping-related apps in the Google Play Store, it appears that the Apple vaping app ban would have had a minimal effect on adults seeking to switch away from smoking or seeking to vape more safely. Most vaping-related apps in the Google Play Store were for purposes related to continuing vaping and had limited age-based access restrictions. Few apps were for controlling device settings, assisting with quitting smoking or vaping, or disseminating information about safer vaping.

\section{Conflicts of Interest}

None declared.

\section{References}

1. Walley SC, Wilson KM, Winickoff JP, Groner J. A Public Health Crisis: Electronic Cigarettes, Vape, and JUUL. Pediatrics 2019 Jun 23;143(6):e20182741. [doi: 10.1542/peds.2018-2741] [Medline: 31122947]

2. Budney AJ, Sargent JD, Lee DC. Vaping cannabis (marijuana): parallel concerns to e-cigs? Addiction 2015 Dec 12;110(11):1699-1704 [FREE Full text] [doi: 10.1111/add.13036] [Medline: 26264448] 
3. King BA, Jones CM, Baldwin GT, Briss PA. The EVALI and Youth Vaping Epidemics — Implications for Public Health. N Engl J Med 2020 Feb 20;382(8):689-691. [doi: 10.1056/nejmp1916171]

4. Erku D, Gartner CE, Morphett K, Snoswell CL, Steadman KJ. Nicotine vaping products as a harm reduction tool among smokers: Review of evidence and implications for pharmacy practice. Res Social Adm Pharm 2020 Oct;16(9):1272-1278. [doi: 10.1016/j.sapharm.2020.02.002] [Medline: 32061550]

5. Gordon T, Fine J. Cornering the Suspects in Vaping-Associated EVALI. N Engl J Med 2020 Feb 20;382(8):755-756. [doi: 10.1056/nejme2001065]

6. Miech R, Johnston L, O’Malley PM, Bachman JG, Patrick ME. Adolescent Vaping and Nicotine Use in 2017-2018 U.S. National Estimates. N Engl J Med 2019 Jan 10;380(2):192-193. [doi: 10.1056/nejmc1814130]

7. Youth Tobacco Use: Results from the National Youth Tobacco Survey. Food And Drug Administration. 2019. URL: https:/ /www.fda.gov/tobacco-products/youth-and-tobacco/youth-tobacco-use-results-national-youth-tobacco-survey [accessed 2020-05-06]

8. Fried I, Allen M. Exclusive: Apple to remove vaping apps from store. Axios. 2019. URL: https://www.axios.com/ exclusive-apple-to-remove-vaping-apps-from-store-8669fd94-e92a-4ce4-a9e2-ce5afa598b67.html [accessed 2020-05-06]

9. Nutt DJ, Phillips LD, Balfour D, Curran HV, Dockrell M, Foulds J, et al. Estimating the harms of nicotine-containing products using the MCDA approach. Eur Addict Res 2014 Apr 3;20(5):218-225 [FREE Full text] [doi: 10.1159/000360220] [Medline: 24714502]

10. Ghosh S, Drummond M. Electronic cigarettes as smoking cessation tool: are we there? Curr Opin Pulm Med 2017;23(2):0348. [doi: $10.1097 / \mathrm{mcp} .0000000000000348$ ]

11. Hajek P, Phillips-Waller A, Przulj D, Pesola F, Myers Smith K, Bisal N, et al. A Randomized Trial of E-Cigarettes versus Nicotine-Replacement Therapy. N Engl J Med 2019 Feb 14;380(7):629-637. [doi: 10.1056/nejmoa1808779]

12. Singh S, Windle SB, Filion KB, Thombs BD, O'Loughlin JL, Grad R, et al. E-cigarettes and youth: Patterns of use, potential harms, and recommendations. Prev Med 2020 Mar 03;133:106009. [doi: 10.1016/j.ypmed.2020.106009] [Medline: 32027913]

13. National Academy of Science Engineering and Medicine. Public Health Consequences of E-Cigarettes. Washington, DC: The National Academies Press; 2018.

14. Azagba S, Manzione L, Shan L, King J. Trends in Smoking Behaviors Among US Adolescent Cigarette Smokers. Pediatrics 2020 Mar 03;145(3):e20193047. [doi: 10.1542/peds.2019-3047] [Medline: 32015140]

15. Miech R, Schulenberg J, Johnston L. National adolescent drug trends in 2018. In: Monitoring the Future. Ann Arbor, MI: University of Michigan; 2019.

16. Boykan R, Goniewicz ML, Messina CR. Evidence of Nicotine Dependence in Adolescents Who Use Juul and Similar Pod Devices. Int J Environ Res Public Health 2019 Jun 17;16(12):2135 [FREE Full text] [doi: 10.3390/ijerph16122135] [Medline: $\underline{31212888]}$

17. 2016 Surgeon General's Report: Cigarette Use Among Youth and Young Adults. Centers for Disease Control and Prevention. 2016. URL: https://www.cdc.gov/tobacco/data_statistics/sgr/e-cigarettes/index.htm [accessed 2020-05-06]

18. Gravely S, Driezen P, Ouimet J, Quah ACK, Cummings KM, Thompson ME, et al. Prevalence of awareness, ever-use and current use of nicotine vaping products (NVPs) among adult current smokers and ex-smokers in 14 countries with differing regulations on sales and marketing of NVPs: cross-sectional findings from the ITC Project. Addiction 2019 Jun 20;114(6):1060-1073 [FREE Full text] [doi: 10.1111/add.14558] [Medline: $\underline{\text { 30681215] }}$

19. Erku DA, Kisely S, Morphett K, Steadman KJ, Gartner CE. Framing and scientific uncertainty in nicotine vaping product regulation: An examination of competing narratives among health and medical organisations in the UK, Australia and New Zealand. Int J Drug Policy 2020 Apr;78:102699. [doi: 10.1016/j.drugpo.2020.102699] [Medline: 32086156]

20. Center for Tobacco-Free Kids. 2020. URL: https://www.tobaccofreekids.org/assets/factsheets/0398.pdf [accessed 2020-05-06]

21. Fischer B, Russell C, Sabioni P, van den Brink W, Le Foll B, Hall W, et al. Lower-Risk Cannabis Use Guidelines: A Comprehensive Update of Evidence and Recommendations. Am J Public Health 2017 Aug;107(8):e1-e12. [doi: 10.2105/ajph.2017.303818]

22. Aston ER, Scott B, Farris SG. A qualitative analysis of cannabis vaporization among medical users. Exp Clin Psychopharmacol 2019 Aug;27(4):301-308 [FREE Full text] [doi: 10.1037/pha0000279] [Medline: 31120278]

23. Tashkin DP. How beneficial is vaping cannabis to respiratory health compared to smoking? Addiction 2015 Dec 16;110(11):1706-1707. [doi: 10.1111/add.13075] [Medline: 26471152]

24. Borodovsky JT, Crosier BS, Lee DC, Sargent JD, Budney AJ. Smoking, vaping, eating: Is legalization impacting the way people use cannabis? Int J Drug Policy 2016 Oct;36:141-147 [FREE Full text] [doi: 10.1016/j.drugpo.2016.02.022] [Medline: 26992484]

25. Schauer GL, Njai R, Grant-Lenzy AM. Modes of marijuana use - smoking, vaping, eating, and dabbing: Results from the 2016 BRFSS in 12 States. Drug Alcohol Depend 2020 Apr 01;209:107900. [doi: 10.1016/j.drugalcdep.2020.107900] [Medline: 32061947]

26. Meacham MC, Paul MJ, Ramo DE. Understanding emerging forms of cannabis use through an online cannabis community: An analysis of relative post volume and subjective highness ratings. Drug Alcohol Depend 2018 Jul 01;188:364-369 [FREE Full text] [doi: 10.1016/j.drugalcdep.2018.03.041] [Medline: 29883950] 
27. Giroud C, de Cesare M, Berthet A, Varlet V, Concha-Lozano N, Favrat B. E-Cigarettes: A Review of New Trends in Cannabis Use. Int J Environ Res Public Health 2015 Aug 21;12(8):9988-10008 [FREE Full text] [doi: 10.3390/ijerph120809988] [Medline: 26308021]

28. Leas EC, Nobles AL, Caputi TL, Dredze M, Smith DM, Ayers JW. Trends in Internet Searches for Cannabidiol (CBD) in the United States. JAMA Netw Open 2019 Oct 02;2(10):e1913853 [FREE Full text] [doi:

10.1001/jamanetworkopen.2019.13853] [Medline: 31642924]

29. Vandrey R, Raber JC, Raber ME, Douglass B, Miller C, Bonn-Miller MO. Cannabinoid Dose and Label Accuracy in Edible Medical Cannabis Products. JAMA 2015 Jun 23;313(24):2491-2493. [doi: 10.1001/jama.2015.6613] [Medline: 26103034]

30. Bonn-Miller MO, Loflin MJE, Thomas BF, Marcu JP, Hyke T, Vandrey R. Labeling Accuracy of Cannabidiol Extracts Sold Online. JAMA 2017 Dec 07;318(17):1708-1709 [FREE Full text] [doi: 10.1001/jama.2017.11909] [Medline: 29114823]

31. Friedman AS. Association of vaping-related lung injuries with rates of e-cigarette and cannabis use across US states. Addiction 2020 Aug 25:00-00. [doi: 10.1111/add.15235] [Medline: 32840932]

32. Ghinai I, Navon L, Gunn JK, Duca LM, Brister S, Love S, et al. Characteristics of Persons Who Report Using Only Nicotine-Containing Products Among Interviewed Patients with E-cigarette, or Vaping, Product Use-Associated Lung Injury - Illinois, August-December 2019. MMWR Morb Mortal Wkly Rep 2020 Jan 24;69(3):84-89 [RREE Full text] [doi: 10.15585/mmwr.mm6903e1] [Medline: 31971930]

33. Krishnasamy VP, Hallowell BD, Ko JY, Board A, Hartnett KP, Salvatore PP, Lung Injury Response Epidemiology/Surveillance Task Force. Update: Characteristics of a Nationwide Outbreak of E-cigarette, or Vaping, Product Use-Associated Lung Injury - United States, August 2019-January 2020. MMWR Morb Mortal Wkly Rep 2020 Jan 24;69(3):90-94 [FREE Full text] [doi: 10.15585/mmwr.mm6903e2] [Medline: 31971931]

34. Hall W, Gartner C, Bonevski B. Lessons from the public health responses to the US outbreak of vaping-related lung injury. Addiction 2020 May 04:00-00. [doi: 10.1111/add.15108] [Medline: 32364274]

35. Rathbone AL, Prescott J. The Use of Mobile Apps and SMS Messaging as Physical and Mental Health Interventions: Systematic Review. J Med Internet Res 2017 Aug 24;19(8):e295 [FREE Full text] [doi: 10.2196/jmir.7740] [Medline: 28838887]

36. Fox S, Duggan M. Mobile Health 2012. Pew Research Center. 2012. URL: https://www.pewresearch.org/internet/2012/11/ 08/mobile-health-2012/ [accessed 2020-05-06]

37. Carroll JK, Moorhead A, Bond R, LeBlanc WG, Petrella RJ, Fiscella K. Who Uses Mobile Phone Health Apps and Does Use Matter? A Secondary Data Analytics Approach. J Med Internet Res 2017 Apr 19;19(4):e125 [FREE Full text] [doi: 10.2196/jmir.5604] [Medline: 28428170 ]

38. Clement J. Number of apps available in leading app stores as of 1st quarter 2020. Statista. URL: https://www.statista.com/ statistics/276623/number-of-apps-available-in-leading-app-stores/\#statisticContainer [accessed 2020-08-25]

39. Hestres LE. App Neutrality: Apple's App Store and Freedom of Expression Online. SSRN Journal 2013;7:1265-1280. [doi: 10.2139/ssrn.2032050]

40. Viswanathan P. iOS App Store vs Google Play Store: Which is better for app developers? Lifewire. 2020 Mar 09. URL: https://www.lifewire.com/ios-app-store-vs-google-play-store-for-app-developers-2373130 [accessed 2020-05-07]

41. Restricted Content Developer Policy Center. Google Play. 2020. URL: https://play.google.com/about/restricted-content/ [accessed 2020-05-11]

42. Apple. App Store Review Guidelines. URL: https://developer.apple.com/app-store/review/guidelines/\#physical-harm [accessed 2020-05-10]

43. Apple removes vaping apps from app store. BBC. 2019 Nov 15. URL: https://www.bbc.com/news/technology-50434755 [accessed 2020-05-07]

44. Stickstones J. What Apple's Vape App Ban Means To You. Planet of the Vapes. 2019 Nov 22. URL: https://www. planetofthevapes.com/blogs/blog/what-apples-vape-app-ban-means-to-you [accessed 2020-05-07]

45. Medal A. Assessing the Effects of Apple's Ban on Vaping Apps. Entrepreneur. 2019 Nov 27. URL: https://www. entrepreneur.com/article/342899 [accessed 2020-05-07]

46. McDonald J. Apple Removes Vaping Content from App Store. Vaping360. 2019 Nov 16. URL: https://vaping360.com/ vape-news/86676/apple-removes-vaping-apps-from-the-app-store/ [accessed 2020-05-07]

47. Vogel E, Ramo D, Rubinstein M, Delucchi KL, Darrow S, Costello C, et al. Effects of Social Media on Adolescents' Willingness and Intention to Use E-Cigarettes: An Experimental Investigation. Nicotine Tob Res 2020 Jan 08:00-00. [doi: 10.1093/ntr/ntaa003] [Medline: $\underline{31912147]}$

48. Camenga D, Gutierrez K, Kong G, Cavallo D, Simon P, Krishnan-Sarin S. E-cigarette advertising exposure in e-cigarette naïve adolescents and subsequent e-cigarette use: A longitudinal cohort study. Addict Behav 2018 Jun;81:78-83 [FREE Full text] [doi: 10.1016/j.addbeh.2018.02.008] [Medline: 29432916]

49. Weaver ER, Horyniak DR, Jenkinson R, Dietze P, Lim MS. "Let's get Wasted!" and Other Apps: Characteristics, Acceptability, and Use of Alcohol-Related Smartphone Applications. JMIR Mhealth Uhealth 2013 Jul 25;1(1):e9 [FREE Full text] [doi: 10.2196/mhealth.2709] [Medline: 25100681] 
50. Tofighi B, Chemi C, Ruiz-Valcarcel J, Hein P, Hu L. Smartphone Apps Targeting Alcohol and Illicit Substance Use: Systematic Search in in Commercial App Stores and Critical Content Analysis. JMIR Mhealth Uhealth 2019 Apr 22;7(4):e11831 [FREE Full text] [doi: 10.2196/11831] [Medline: 31008713]

51. Haskins BL, Lesperance D, Gibbons P, Boudreaux ED. A systematic review of smartphone applications for smoking cessation. Transl Behav Med 2017 Jun 19;7(2):292-299 [FREE Full text] [doi: 10.1007/s13142-017-0492-2] [Medline: 28527027]

52. Thornton L, Quinn C, Birrell L, Guillaumier A, Shaw B, Forbes E, et al. Free smoking cessation mobile apps available in Australia: a quality review and content analysis. Aust N Z J Public Health 2017 Dec 27;41(6):625-630. [doi: 10.1111/1753-6405.12688] [Medline: 28749591]

53. Regmi D, Tobutt C, Shaban S. Quality and Use of Free Smoking Cessation Apps for Smartphones. Int J Technol Assess Health Care 2018 Sep 18;34(5):476-480. [doi: 10.1017/s0266462318000521]

54. Vilardaga R, Casellas-Pujol E, McClernon JF, Garrison KA. Mobile Applications for the Treatment of Tobacco Use and Dependence. Curr Addict Rep 2019 Jul 9;6(2):86-97 [FREE Full text] [doi: 10.1007/s40429-019-00248-0] [Medline: $\underline{32010548]}$

55. Rajani NB, Weth D, Mastellos N, Filippidis FT. Use of gamification strategies and tactics in mobile applications for smoking cessation: a review of the UK mobile app market. BMJ Open 2019 Jun 17;9(6):e027883. [doi: 10.1136/bmjopen-2018-027883] [Medline: $\underline{31213452]}$

56. Ferron JC, Brunette MF, Geiger P, Marsch LA, Adachi-Mejia AM, Bartels SJ. Mobile Phone Apps for Smoking Cessation: Quality and Usability Among Smokers With Psychosis. JMIR Hum Factors 2017 Mar 03;4(1):e7 [FREE Full text] [doi: 10.2196/humanfactors.5933] [Medline: 28258047]

57. Ramo DE, Popova L, Grana R, Zhao S, Chavez K. Cannabis Mobile Apps: A Content Analysis. JMIR Mhealth Uhealth 2015 Aug 12;3(3):e81 [FREE Full text] [doi: 10.2196/mhealth.4405] [Medline: 26268634]

58. Abroms LC, Lee Westmaas J, Bontemps-Jones J, Ramani R, Mellerson J. A content analysis of popular smartphone apps for smoking cessation. Am J Prev Med 2013 Dec;45(6):732-736 [FREE Full text] [doi: 10.1016/j.amepre.2013.07.008] [Medline: 24237915]

59. Stoyanov SR, Hides L, Kavanagh DJ, Zelenko O, Tjondronegoro D, Mani M. Mobile app rating scale: a new tool for assessing the quality of health mobile apps. JMIR Mhealth Uhealth 2015 Mar 11;3(1):e27 [FREE Full text] [doi: 10.2196/mhealth.3422] [Medline: 25760773]

60. Cox S, Leigh NJ, Vanderbush TS, Choo E, Goniewicz ML, Dawkins L. An exploration into "do-it-yourself" (DIY) e-liquid mixing: Users' motivations, practices and product laboratory analysis. Addict Behav Rep 2019 Jul;9:100151 [FREE Full text] [doi: 10.1016/j.abrep.2018.100151] [Medline: 31193745]

61. Davis B, Dang M, Kim J, Talbot P. Nicotine concentrations in electronic cigarette refill and do-it-yourself fluids. Nicotine Tob Res 2015 Mar 26;17(2):134-141 [FREE Full text] [doi: 10.1093/ntr/ntu080] [Medline: 24862971]

62. Lanz C, Mattsson J, Soydaner U, Brenneisen R. Medicinal Cannabis: In Vitro Validation of Vaporizers for the Smoke-Free Inhalation of Cannabis. PLoS One 2016 Jan 19;11(1):e0147286 [FREE Full text] [doi: 10.1371/journal.pone.0147286] [Medline: 26784441]

63. Clinical Practice Guideline Treating Tobacco Use Dependence 2008 Update Panel, Liaisons, Staff. A clinical practice guideline for treating tobacco use and dependence: 2008 update. A U.S. Public Health Service report. Am J Prev Med 2008 Aug;35(2):158-176 [FREE Full text] [doi: 10.1016/j.amepre.2008.04.009] [Medline: 18617085]

64. Shilton K, Greene D. Linking Platforms, Practices, and Developer Ethics: Levers for Privacy Discourse in Mobile Application Development. J Bus Ethics 2017 Mar 28;155(1):131-146. [doi: 10.1007/s10551-017-3504-8]

\section{Abbreviations}

DIY: do-it-yourself

EVALI: electronic or vaping product use associated lung injury

IP: internet protocol

MARS: Mobile App Rating Scale

THC: tetrahydrocannabinol

URL: uniform resource locator 
Edited by G Eysenbach; submitted 13.05.20; peer-reviewed by J Brigham, D Levesque; comments to author 10.07.20; revised version received 01.09.20; accepted 24.09.20; published 13.11.20

Please cite as:

Meacham MC, Vogel EA, Thrul J

Vaping-Related Mobile Apps Available in the Google Play Store After the Apple Ban: Content Review

$J$ Med Internet Res 2020;22(11):e20009

URL: http://www.jmir.org/2020/11/e20009/

doi: 10.2196/20009

PMID: 33185565

CMeredith C Meacham, Erin A Vogel, Johannes Thrul. Originally published in the Journal of Medical Internet Research (http://www.jmir.org), 13.11.2020. This is an open-access article distributed under the terms of the Creative Commons Attribution License (https://creativecommons.org/licenses/by/4.0/), which permits unrestricted use, distribution, and reproduction in any medium, provided the original work, first published in the Journal of Medical Internet Research, is properly cited. The complete bibliographic information, a link to the original publication on http://www.jmir.org/, as well as this copyright and license information must be included. 